\title{
45 anos de Pós-Graduação em Educação na Universidade Federal do Paraná: situação e desafios
}

\section{5 years of the Education Postgraduate Program at the Federal University of Parana: status and challenges}

\author{
Carlos Roberto Jamil Cury*
}

\begin{abstract}
RESUMO
Este artigo, inspirado no texto proferido na comemoração de uma efeméride do Programa de Pós-Graduação em Educação da Universidade Federal do Paraná, tem como objetivo assinalar o sentido e o significado da PósGraduação no Brasil. A trajetória do Programa resume em si as dimensões do processo de desenvolvimento da Pós-Graduação em Educação. Concomitantemente ao seu crescimento quantitativo, para o qual a ação consciente do Estado Brasileiro foi fundamental por meio dos Planos Nacionais de Pós-Graduação, houve a irradiação da pesquisa sobre os problemas educacionais do ponto de vista da qualidade. Aos poucos, a PósGraduação foi se constituindo como um intelectual coletivo e autônomo da área. Como expressão disso, destaquem-se a presença do Programa nas reuniões anuais da área, as publicações e o empenho na formação de inúmeros mestres/mestras e doutores/doutoras. Ao mesmo tempo, o programa, junto com os outros programas de pós-graduação em Educação, participando da organização da educação nacional, não deixa de estar sujeito aos processos de avaliação conduzidos pela CAPES/MEC. O artigo assinala os riscos de retrocesso no conjunto da pós-graduação por políticas de governo que venham a ser desconstrutoras de avanços colhidos no financiamento e nos processos de participação dos pares na qualificação da área.
\end{abstract}

Palavras-chave: Pós-Graduação em Educação no Brasil. Programas de Pós-Graduação em Educação. Programa de Pós-Graduação em Educação da Universidade Federal do Paraná.

${ }^{*}$ Pontifícia Universidade Católica de Minas Gerais. Belo Horizonte, Minas Gerais, Brasil. E-mail: crjcury.bh@terra.com.br - https://orcid.org/0000-0001-5555-6602 


\begin{abstract}
This paper, which was inspired by a text pronounced in an anniversary celebration of the Education Postgraduate Program at the Federal University of Parana, aims at emphasizing the purpose and meaning of Postgraduation in Brazil. The Program journey itself summarizes the dimensions of the development process in the Education Postgraduation. Concomitant with its quantitative expansion, for which the Brazilian State conscious acts were essential by means of the Postgraduate National Plans, there was a research spreading on educational problems from the point of view of quality. Gradually, Postgraduation has been establishing an intellectual autonomous collective in the field. As its expression we punctuate the presence of the Program at annual meetings on that subject, its publications and dedication to countless students' master and doctoral education. Simultaneously, the program, along with other postgraduate programs in Education, participating in the national education setup, is not free of being subject to evaluation processes conducted by CAPES/MEC. This article points out retreat risks at postgraduation as a whole through governmental policies which may deconstruct advances supported by funding and arrangements of peers' participation in qualifying the field.
\end{abstract}

Keywords: Brazilian Postgraduation in Education. Education Postgraduate Programs. Education Postgraduate Program at the Federal University of Parana.

\title{
Saudação inicial:
}

\section{5 anos: bodas de rubi!}

O rubi, gema de um vermelho peculiar, é dotado de uma resistência que assinala sua consolidação robusta e potente. Esse vermelho tão próprio dele é também lembrado como a "cor da paixão e do amor", além de símbolo do fogo, o qual desprende calor e luz. Ainda, compara-se ao fogo de Heráclito, símbolo do fluir da realidade, dotado de um movimento incessante que se transforma sempre em avanços sob a combustão de algo, sem perder, contudo, a estabilidade. Por isso, crê-se que o vermelho do rubi fortalece a conjugação de um protagonismo dinâmico e a recusa do caráter estático das energias malsãs...

Hoje é dia de festa, de avivar-se com a presença deste programa no âmbito da pós-graduação e seus desdobramentos na educação nacional. É justo haver uma celebração festiva e solene, tão logo possível. É dia de alegrar-se com os ecos de tantos egressos no exercício da docência, da gestão e em outros tantos campos da educação nacional. 


\section{Introdução}

O que significa comemorar esta data?

Ela é um momento paradoxal em que solidão e comunicação se aproximam. Pela solidão, um recuo oportuno para se refletir sobre as realizações feitas, fazer um balanço e, abastecido por este, dobrar-se sobre si mesmo (re-flexão). Pela comunicação, torna-se imperativo pensar em um novo começo, em um renascer que se abra para caminhos mais novos, para uma presença tão ou mais significativa quanto foram esses 45 anos de comunicação/responsabilidade social/extensão.

Os 45 anos do Programa de Pós-Graduação em Educação da UFPR são uma oportunidade aberta em vista de uma retomada analítica sobre a área da educação, considerando-se o sistema nacional de pós-graduação.

Por que oportunidade?

Oportunidade é um momento propício para se rever, crescer e avançar. A origem etimológica desse termo dá o que pensar. Em sua base está a náutica. Sair de um "porto" e dirigir-se a outro é o roteiro de uma viagem que vê no próximo "porto" o momento propício para rever trajetos, riscar novos mapas e - por que não? - descansar e festejar a chegada à terra firme?

Oportunidade é passar por um "porto". Por que não fazer desse "porto", sempre provisório, uma "porta" para uma viagem melhor, melhor sinalizada, mais segura? Sendo assim, correndo riscos de alguma turbulência, gostaria de refletir, em conjunto, sobre algumas preocupações que podem afetar o traçado da viagem futura.

O marco de 45 anos do PPGE-UFPR tem sua origem no ano de 1975, 10 anos após a institucionalização da pós-graduação no sistema universitário nacional, dado pelo Parecer 977/65, 2 anos antes da formalização da Associação Nacional de Pós-Graduação em Educação (ANPEd).

\section{Os números contam...}

O ano de 1965 institucionaliza, de modo formal e sistemático, a PósGraduação no Brasil. Em que pese estarmos na ditadura militar, o Parecer CFE 977/65, consequente ao ditame da lei n. 4.024/61, propiciou uma ação consciente do Estado brasileiro em criar elites culturais e científicas, em vista 
de um modelo de desenvolvimento que, ao projetar uma Nação-Potência na economia e nas armas, não poderia discriminar o conjunto das ciências. Isso não poderia deixar de impulsionar as ciências humanas e a própria vida universitária. Apesar da cassação de muitos professores, até então atuantes, da própria censura, os governantes de então entenderam a necessidade de haver no país o desenvolvimento da ciência. Cumpria fazer da pós-graduação um lugar de avanço do conhecimento e do conhecimento aplicado ${ }^{1}$.

De fato, não se pode esquecer que, sem pesquisa básica sólida, não há autonomia nacional. Uma pesquisa sólida é sempre crítica porque faz o conhecimento avançar não raras vezes em desacordo fundamentado com o conhecimento existente.

Pesquisar é ir do conhecido ao desconhecido e fazer desse até então "desconhecido" um "novo conhecido". Se a pesquisa é a ênfase da pós-graduação em relação à graduação, então os números nos dizem um pouco do quanto as áreas avançaram em matéria de novos e originais conhecimentos sobre os mais diversos campos.

Do ponto de vista da cobertura nacional, os números revelam que o acesso ao sistema nacional de pós-graduação vem cumprindo sua tarefa de conferir aos seus matriculados os graus acadêmicos no nível de mestrado e/ou de doutorado. Também nós nos tornamos conscientes da quantidade de resultados inovadores que a pós-graduação vem propiciando ao conjunto do sistema universitário, especialmente à graduação e, por extensão, à sociedade.

Para efeito de uma referência comparativa em matéria de números e para dar apenas um esboço da grandeza do sistema de pós-graduação como um todo, sem o afã de comparações estatísticas sistemáticas, tomo a liberdade de citar um pequeno artigo de minha autoria, publicado em um número do Boletim ANPEd (CURY, 1987) ${ }^{2}$.

O então denominado presidente de área (hoje coordenador/a) e membro do Conselho Técnico-Científico da CAPES coletou dados gerais do biênio 1984/1985, por ocasião da avaliação dos cursos.

Tomando o ano de 1941 como referência inicial, até 1985 havia se titulado no país um total aproximado de 49.000 mestres e 6.000 doutores, sendo que na área de Ciências Humanas e Sociais estes números foram 17.900 e 1.600 respectivamente. Atualmente, formam-se, cada ano, no conjunto

1 Sobre esse parecer e os resultados esperados e não esperados da pós-graduação, cf. Cury (2005); Oliveira (1980); Saviani (2005).

2 Cf. ao final, em anexo, alguns gráficos desse período apenas como espelho comparativo em relação à situação atual. 
das áreas, aproximadamente 6.000 mestres e 600 doutores. (CURY, 1987 , p. 3$)^{3}$

O sistema cresceu, espetacularmente, em quantidade e em qualidade. Mas, essa expansão não se deu de modo espontâneo e há razões para tal. E esse crescimento se deveu a um esforço endógeno do país, das instituições e dos programas, sem deixar de citar a qualificação obtida no exterior.

Tomando agora a nossa subárea da Educação como referência, há exatos 55 anos, tínhamos um só programa: o da PUCRJ. Após o pioneirismo desse programa, houve a instauração de outro mestrado em 1969, seguido de mais um em 1970, de outros 3 em 1971 e mais 7 em 1972. O da Universidade Federal do Paraná se inclui em 1975. Chegamos, em 1984, a 27 cursos de mestrado credenciados.

Os cursos de doutorado se instauram a partir de 1976. Seis anos após, em 1982, haverá 7 programas. Esse número de doutorados permanece inclusive na avaliação da Capes de 1986 do biênio 84/85. Fomos crescendo de 30 programas em 1987 aos 73 programas em 2003 (mais de 2,3 vezes em 18 anos), dos quais tínhamos 45 cursos de mestrado e 28 cursos articulados de mestrado e de doutorado.

Entrementes, em uma República Federativa em cuja Constituição se lê, no artigo $3^{\circ}$, ser um de seus objetivos fundamentais a redução das disparidades regionais, as políticas públicas do PNPG 2005-2010, atualizadas pelo PNPG 2011-2020, perseguem um equilíbrio federativo.

Outro ponto de vista significativo é o da organização da educação nacional, que distingue, nos sistemas de educação dos entes federativos, os sistemas públicos federais e estaduais dos quais fazem parte as redes particulares autorizadas.

Em 1984, o sistema público federal abrigava 17 cursos de mestrado e 2 doutorados, aí compreendida uma fundação pública de direito privado cuja extinção representou uma baixa na pluralidade institucional e uma perda na busca da excelência. O sistema público estadual absorvia 3 mestrados e 2 doutorados. Já a rede privada confessional do sistema federal abrigava 7 cursos de mestrado e 3 de doutorado.

3 A referência mais próxima que disponho de uma dissertação de mestrado é a de Virgínia Bicudo Leone (1910 - 2003) defendida na Escola de Sociologia e Política de São Paulo sob o título Atitudes raciais de pretos e mulatos em São Paulo, em 1945. Um artigo dela, mulher negra, normalista e psicanalista, pode ser lido em Bicudo (1947). A SBPC, em seu site, a aponta como uma das mais ilustres mulheres cientistas. 
Voltando agora o olhar para a formação de mestres e doutores, observa-se que, entre 1973 e 1986, a educação titulou 3.584 mestres (em 13 anos foram aproximadamente 275 mestres por ano) e 109 doutores (em média 8,3 doutores por ano).

Pelos dados da avaliação dos anos 1985/86, registraram-se, no biênio, 2.634 alunos matriculados no mestrado e 313 no doutorado. O tempo médio de titulação dos estudantes nesse biênio apresentava 63 meses para o mestrado e 68 meses para o doutorado. Em 1986, havia 448 bolsas de mestrado e 33 de doutorado. Tínhamos 561 professores permanentes no conjunto dos programas. Registrávamos ainda que desses 561 professores, 112 ainda eram mestres (na maioria em regime de doutoramento). Publicamos, no biênio, 112 livros e assinalavam-se 246 relatórios de pesquisa.

O Programa de Pós-Graduação em Educação da Universidade Federal do Paraná, nota 6 na última avaliação, com 6 áreas de concentração, conta, hoje, com 77 professores permanentes e 9 colaboradores. Nesses 45 anos, demonstra haver cooperado com o desenvolvimento da área, com 1.336 mestres e mestras, ou seja, em média, mais de 28 mestres/ano e com 323 doutores e doutoras, vale dizer em torno de 19 por ano.

\section{E a área se complexificou...}

Forçoso é reconhecer que a área de Educação se complexificou. $\mathrm{O}$ seu crescimento interno é cada vez maior, mais plural com a inclusão dos mestrados profissionais. Sua abrangência, por conta dos processos avaliativos da Capes, sempre polêmicos, encontra nas discussões internas a busca do rigor e sofisticação, seja para cultivar a qualidade severamente mantida, seja para amparar individualmente o pesquisador e o estudante. Esse amparo, exigência advinda da Constituição, deve contar com fomento e apoio do $\mathrm{CNPq}$ e das FAPs. É preciso registrar ainda a atuação das Pró-Reitorias de Pesquisa e PósGraduação das universidades, seja institucionalmente, seja por meio do Fórum de Pró-Reitores de Pesquisa e Pós-Graduação. Veja-se o disposto no art. 218 da Carta Magna (BRASIL, 1988):

O Estado promoverá e incentivará o desenvolvimento científico, a pesquisa, a capacitação científica e tecnológica e a inovação. 
$\S 1^{\circ}$ A pesquisa científica básica e tecnológica receberá tratamento prioritário do Estado, tendo em vista o bem público e o progresso da ciência, tecnologia e inovação.

$\S 2^{\circ}$ A pesquisa tecnológica voltar-se-á preponderantemente para a solução dos problemas brasileiros e para o desenvolvimento do sistema produtivo nacional e regional.

$\S 3^{\circ} \mathrm{O}$ Estado apoiará a formação de recursos humanos nas áreas de ciência, pesquisa, tecnologia e inovação, inclusive por meio do apoio às atividades de extensão tecnológica, e concederá aos que delas se ocupem meios e condições especiais de trabalho.

Tal promoção e incentivo, tendo em vista um padrão de qualidade do ensino e da pesquisa, de acordo com o art. 214 da Constituição, têm como instrumento mobilizador o Plano Nacional de Educação (PNE). E aí surgem os objetivos da melhoria da qualidade do ensino e da promoção humanística, científica e tecnológica do país.

Também a LDB (BRASIL, 1996), em seu art. 86, deixa claro:

As instituições de educação superior constituídas como universidades, integrar-se-ão, também, na sua condição de instituições de pesquisa, ao Sistema Nacional de Ciência e Tecnologia, nos termos da legislação específica.

Acompanhando este crescimento e complexificação, a ANPEd também se empenhou no aperfeiçoamento de suas Reuniões Anuais, com criação de Grupos de Pesquisa, e na constituição de uma Comissão Científica para a análise das propostas de comunicações, minicursos e mesas dentro das reuniões anuais. Paralela e concomitantemente, cresceu em importância interna a reunião do Fórum de Coordenadores, o Fórum de Editores de Periódicos da Área de Educação (FEPAE) e a publicação da Revista Brasileira de Educação (RBE). Vale aqui a retomada de um texto de Fávero (1996, p. 57):

Constata-se ainda que a ANPEd se firmou como representante dos programas, tendo organizado recentemente o Fórum de Coordenadores, os quais voltaram a ter, desde 1991, reuniões técnicas anuais. Firmouse também como interlocutora das agências de coordenação da pósgraduação e de fomento à pesquisa, assim como parceira da SBPC, 
participando da organização de suas reuniões anuais e da Comissão das Sociedades Científicas. Atualmente lidera uma salutar abertura da Educação para as outras áreas das Ciências Humanas e Sociais.

O histórico e a contextualização do site do programa de Pós-Graduação em Educação da Universidade Federal do Paraná é bastante elucidativo a esse respeito.

Citando trechos do site (UFPR, 2020), temos:

A criação do Doutorado, no ano de 2002, implicou na definição de uma nova organização curricular composta por Área de Concentração, três áreas temáticas, e ligadas a essas áreas temáticas, as linhas de pesquisa. [...] No intuito de atender a tal realidade, em princípio regional, o Programa de Pós-Graduação definiu como seus objetivos principais: Qualificação de profissionais para o exercício docente no sistema de ensino superior; qualificação de pesquisadores no campo da educação; qualificação de profissionais para o exercício pedagógico-educacional em sistemas educacionais convencionais e não convencionais; ampliação e desenvolvimento do conhecimento e da crítica na área de educação; contribuição à construção da identidade da educação nacional, em seu pensamento pedagógico na prática, e do sentido de solidariedade internacional.

[...] na metade do ano de 2008, após um semestre de debates, o colegiado do PPGE aprovou as novas normas do Programa, que incluíram um avanço significativo na sua organização, gestão e avaliação. A reforma curricular iniciada em 2009 apontava para a necessidade de uma reestruturação ampla do Programa, com a finalização das áreas temáticas e de algumas linhas de pesquisa, além do desdobramento de outras; com uma melhor definição dos créditos mínimos necessários à formação; com o estabelecimento de disciplinas que colocassem os alunos e docentes em melhor articulação com os projetos de pesquisa. Esse processo culminou em uma nova estrutura curricular aprovada em 2010.

\section{Mas ainda há o que fazer...}

Se tomarmos a rápida expansão do ensino superior, especialmente a partir de 1997, e a articularmos com as exigências de titulação postas na Lei 
de Diretrizes e Bases da Educação Nacional (BRASIL, 1996), em seu art. 524, pode-se afirmar que continua a haver um espaço para a formação de mestres e de doutores. Afinal, o número de professores a serem obrigatoriamente titulados cresceu, as exigências de titulação são imperativas e o número de programas recomendados e avaliados pela Capes, credenciados pelo Conselho Nacional de Educação, não conseguem atender toda a demanda. Várias são as estratégias das metas da Lei n ${ }^{\circ} 13.005$ (BRASIL, 2014) que ressaltam a importância dessa formação.

É o caso das estratégias n. $4.16 ; 5.6 ; 12.12$; das 15 estratégias da meta 14 , meta que prevê

elevar gradualmente o número de matrículas na pós-graduação stricto sensu, de modo a atingir a titulação anual de 60.000 (sessenta mil) mestres e 25.000 (vinte e cinco mil) doutores. [...]

Meta 16: formar, em nível de pós-graduação, $50 \%$ (cinquenta por cento) dos professores da educação básica, até o último ano de vigência deste PNE, e garantir a todos (as) os (as) profissionais da educação básica formação continuada em sua área de atuação, considerando as necessidades, demandas e contextualizações dos sistemas de ensino.

E a meta 18.4 dispõe que se preveja "nos planos de Carreira dos profissionais da educação dos Estados, do Distrito Federal e dos Municípios, licenças remuneradas e incentivos para qualificação profissional, inclusive em nível de pós-graduação stricto sensu" (BRASIL, 2014).

Resulta daí uma forte tensão entre a grande demanda e a oferta qualificada, apesar do crescimento dos programas hoje. De acordo com o documento da área de 2017, ela contava, "em setembro de 2016, com 246 cursos de Pósgraduação, sendo 128 de Mestrado Acadêmico, 74 de Doutorado e 44 de Mestrado Profissional. Tais cursos se organizam em 172 Programas, 74 deles com Mestrado e Doutorado Acadêmicos, 54 com Mestrado Acadêmico e 44 com Mestrado Profissional" (BRASIL, 2017).

Apesar de mais de 7.700 matriculados em cursos de mestrado acadêmico, 2.800 em mestrado profissional e 6.500 em cursos de doutorado, segundo os

4 O anteprojeto de Reforma Universitária de 29/07/2005, engavetado no Congresso, exigia das IES, no art. 17, entre outros dispositivos, o de implementar planos de carreira e de capacitação para os docentes. Já o art. 18 exigia para as universidades que $50 \%$ do corpo docente tivesse mestrado ou doutorado e $50 \%$ desses fosse de doutores. Nas Disposições Transitórias, previa-se um tempo de adequação de 6 anos para o total de mestres e de 8 anos para o de doutores (BRASIL, 2005). 
dados do GeoCapes (2018), a demanda não é atendida pela oferta qualificada e credenciada.

Não é à toa que instituições inescrupulosas, geralmente de alguns países sem credibilidade em seus rincões de origem, aproveitam-se do desconhecimento, da ansiedade e da boa-fé de muitos docentes para oferecer-lhes cursos sem validade.

Hoje, no Brasil, segundo os dados de 2017, temos 392.036 docentes no ensino superior. São 160.827 doutores, ou seja, $41,02 \%$ e 154.285 mestres, isto é, $39,35 \%$.

Isso significa que 76.924 docentes do ensino superior, isto é, $19,61 \%$ ainda não possuem o título de mestre, logo, disponíveis para os programas de pós-graduação stricto sensu.

À pós-graduação foi atribuída, também, a tarefa de propiciar a formação pedagógica intrauniversitária, especialmente para a graduação, conforme o artigo 66 da Lei de Diretrizes e Bases e a meta n. 16 do Plano Nacional de Educação. Dela espera-se também a qualificação de profissionais não acadêmicos.

Ao mesmo tempo, postula-se uma interação virtuosa entre Pós-Graduação e Graduação. Tal interação se repõe no atual Plano Nacional de Educação, como acima assinalado, bem como no Plano Nacional de Pós-Graduação 2011-2020.

A ideia de Plano remete a fins institucionalmente estabelecidos para que, por meio de diagnósticos precisos e de meios gerais e financeiros, atinjam-se metas de alta qualificação. Essa ideia de Plano, conquistada nos anos de 1930 para o conjunto da educação, se fez realidade efetiva no âmbito da Pós-Graduação pelos seus Planos Nacionais de Pós-Graduação.

Essa política intencional de formação de quadros obteve inegáveis êxitos e seu modelo é reconhecido internacionalmente. Esse quadro não pode ser entendido sem a presença do Estado na construção de um sistema de pósgraduação, como investimento de longo prazo e que tem trazido aperfeiçoamento ao sistema de pós-graduação. Esse sistema se louva nesse investimento, que representa um fator de qualificação para a carreira acadêmica de docentes e pesquisadores e de profissionais não propriamente acadêmicos.

O que está sendo feito nos últimos 45 anos na UFPR resume em si, de certo modo, essa ampliação consciente e sistemática de um elo que vem de longe, mesmo atingindo um número limitado de pessoas.

Pode-se dizer que a consolidação do sistema nacional de pós-graduação no Brasil, desde os anos de 1960, contou com esse investimento consciente, assegurado pelo Estado, somando a capacidade interna com a adquirida no exterior.

O Plano Nacional de Educação reconhece na pós-graduação um sistema nacional. Um sistema nacional abrange o ordenamento vigente para todo o território nacional valendo tanto para o sistema federal quanto para os sistemas estaduais e municipais, e também para o sistema distrital, dos quais faz parte 
a rede privada autorizada e avaliada. Assim, sua aplicabilidade subordina as instituições do sistema federal, e também as dos outros entes federativos, à ordem jurídica nacional.

De todo modo, a qualificação de docentes e pesquisadores brasileiros no país e no exterior resulta de uma política de pós-graduação por meio de uma ação direta e consciente do Estado cujos resultados podem ser vistos em múltiplos fóruns e na vida acadêmica.

E é esse patrimônio que hoje se encontra em risco. São cortes no investimento nos programas, é a diminuição de bolsas, é o exarar de medidas verticais, e é a malquerência com as ciências humanas e sociais. E esse risco se enquadra, de um lado, em dimensões maiores de congelamento de investimentos e, de outro, no caráter rude, grosseiro e ignorante do que seja uma universidade, do que seja a pesquisa institucionalizada. Prova disso são as constantes investidas no sentido de diminuir ou congelar o orçamento público para o investimento em educação. Veja-se a Emenda Constitucional n ${ }^{\circ}$ 95/2016, e acautelemo-nos em face das PECs n. 186, 187 e 188 do denominado Plano Mais Brasil (2019), que explicitamente pretendem, entre outras propostas do liberalismo conservador, redirecionar os recursos do pré-sal.

Por isso, o atual Plano Nacional de Pós-Graduação e o Plano Nacional de Educação (Lei $\left.n^{0} 13.005 / 2014\right)$ necessitam ser apropriados pela área. Apropriação ao mesmo tempo realista e crítica. Realista porque não temos o direito de não participar, já que somos componentes de uma organização nacional de educação em termos de direito e de cidadania.

A apropriação é crítica porque a crítica é a alma mater da pesquisa e da universidade. Ela é o lugar da circulação do pensamento crítico, avesso aos dogmas e ao senso comum.

\section{Pós-Graduação: um(a) intelectual da área? Qual intelectual?}

Não se deve esperar que os reis se façam filósofos, nem que os filósofos sejam reis. Não se deve também desejá-lo; a posse da força prejudica, inevitavelmente, o livre exercício da razão. Mas se os reis ou povos soberanos - povos que se regem pela lei da igualdade - não permitem que a classe dos filósofos desapareça ou emudeça; se lhes deixarem falar, publicamente, obterão, no estudo dos seus assuntos, os esclarecimentos precisos, de que não se pode prescindir. Os filósofos são, por natureza, inábeis para agitações e propagandas de associações: não são, portanto, suspeitos de proselitismo. (KANT, 1939, p. 75-76). 
A Pós-Graduação em Educação representou e representa um deslocamento institucional em que a produção intelectual e científica foi se soltando dos espaços institucionais individualizados e criando espaços associativos cada vez mais amplos e interativos.

Pode-se dizer que a Pós-Graduação em Educação veio se tornando um intelectual coletivo da área. A Pós-Graduação assumiu essa dimensão do exercício da função de intelectual pelo caráter analítico e crítico da sua vasta produção, pela dissecação de múltiplas facetas da educação e pela socialização dessa contínua passagem de verdades já conhecidas para as ainda não conhecidas. Basta um olhar superficial sobre o número de revistas que circulam pela área, as publicações em capítulos de livros, editoras e livros. E o que dizer do Portal de dissertações e teses?

A Pós-Graduação em Educação preenche o princípio da pluralidade, uma pluralidade aberta e conflitiva em termos epistemológicos, sem ortodoxias. Nesse sentido, a Pós-Graduação veio a se tornar um intelectual orgânico dos problemas da educação, cuja ética não a vincula imediatamente a um grupo ou a um partido ou a uma política de governo. Estamos cumprindo a distinção entre ética e política pelo grau de autonomia que a busca da verdade traz consigo. $\mathrm{Na}$ razão crítica não só se acorda do sono dogmático como também se pode refletir sobre as políticas de hoje e de ontem. É por estar em um pacto com a constante busca de novos conhecimentos que a área trouxe à luz campos da história e da vida social, grupos sociais antes invisibilizados.

Por isso ao orgânico se associa o independente, que não é uma indiferença com relação à dramática situação da educação nacional. Pelo contrário, a área, por meio de suas linhas de pesquisa, vem mostrando a desigualdade e a discriminação que, no conjunto social, perpassam a educação. E tem tomado posição quanto a isso, na elaboração, por exemplo, do Plano Nacional de Educação, na denúncia da falta de investimentos necessários e suficientes para uma educação de qualidade.

O estado atual da educação escolar não anima estudos e pesquisas a criarem fantasias a propósito do que ela não é. A dura realidade dos fatos, oposta à consagração da educação escolar como direito social, direito público subjetivo e direito político, tem conduzido os pesquisadores a serem críticos de uma realidade historicamente iníqua e injusta. Nesse sentido, o pensamento crítico na área não poderia deixar de ser tão denunciador da realidade quão distanciado da política imediata. Lembro aqui a advertência de Gramsci (1978, p. 13-14):

Criar uma nova cultura não significa apenas fazer individualmente descobertas "originais"; significa também, e, sobretudo, difundir criticamente verdades já descobertas, "socializá-las" por assim dizer; 
e, portanto, transformá-las em base de ações vitais, em elemento de coordenação e de ordem intelectual e moral. $\mathrm{O}$ fato de que uma multidão de homens seja conduzida a pensar coerentemente e de maneira unitária a realidade presente é um fato "filosófico" bem mais importante e "original" do que a descoberta, por parte de um "gênio" filosófico, de uma nova verdade que permaneça como patrimônio de pequenos grupos intelectuais.

Enfim, a Pós-Graduação em Educação tornou-se, em sua dimensão institucional, orgânica, independente, coletiva e plural. Pode-se aplicar a ela o que Bobbio (1997, p. 117) diz dos intelectuais:

Do mesmo modo que não constituem uma classe homogênea, e jamais são representados por um partido (pode existir em uma sociedade um partido de intelectuais, mas nunca o partido dos intelectuais), os intelectuais jamais são, salvo no caso das sociedades teocráticas, os depositários de um único corpo de doutrinas: segundo as ideias que sustentam e pelas quais se batem, são progressistas ou conservadores, radicais ou reacionários; segundo as ideologias que defendem, são libertários ou autoritários, liberais ou socialistas; segundo a atitude diante das próprias ideias que sustentam, são céticos ou dogmáticos, laicos ou clericais.

Essa pluralidade não nos deixa vazios. Ela torna o campo do conhecimento científico um campo de disputas na busca da verdade, em que os pontos de vista se medem, se distanciam e se aproximam.

Como diz Bourdieu (1997, p. 89),

as normas cognitivas às quais os pesquisadores devem, de bom ou mau grado, curvar-se no estabelecimento da validade de seus enunciados, as pulsões da libido dominandi científica não podem encontrar satisfação a não ser sob a condição de curvar-se à censura científica do campo. Este lhe exige que utilize as vias da razão científica e do diálogo argumentativo, tais como definidos por ele em um dado momento do tempo, isto é, sublimados em uma libido sciendi que só pode triunfar sobre seus adversários nas regras da arte, opondo a um teorema, a uma demonstração, uma refutação, a um fato científico, outro fato científico. 
As atividades próprias do conhecimento científico se dão, pois, dentro de um campo no qual, retomando Robert Merton, diz Bourdieu (1997, p. 83): “se existe uma verdade, é que a verdade é um lugar de lutas."

Assim, quem busca a verdade busca caminhos, busca direção, busca uma explicação que seja a mais abrangente. Direção, caminhos e aproximações da verdade em um campo de lutas têm sido a procura dos programas de pósgraduação em Educação e, por isso, eles conquistaram a hegemonia cultural na área da Educação não porque tenham a verdade, mas porque a buscam por meio de métodos e concepções plurais em campo de disputas.

Sinal disso é a feição internacionalizada pelas múltiplas trajetórias formativas no exterior, que associadas às próprias do nosso país, dão aos programas, no seu conjunto, um sentido plural e enriquecedor.

Por outro lado, a busca do saber e da verdade, em um sistema nacional de pós-graduação participante da organização da educação nacional, se cruza com o dever do Estado de garantir um padrão de qualidade na manutenção e oferta desse bem. Esse encontro entre autonomia universitária e responsabilidade pelo melhor como dever de Estado - similar àquele que contrasta a ética e a política - mostra-se desafiador e vem se impondo de modo cada vez mais claro na área.

O sistema de pós-graduação cresceu, tornou-se complexo, grande, controlado e avaliado. É possível deixar de se expor ao risco de uma burocratização no modo de gerir esse sistema especialmente no que se refere à avaliação? É possível combinar uma gestão burocrática, inerente à complexidade impessoal do sistema, com o princípio constitucional da gestão democrática e com a autonomia constitucional universitária?

O sistema (aí compreendida a subárea de educação) não debate se a gestão deve ser democrática ou não. O princípio do item VI do artigo 206 da Constituição é claro: a gestão do ensino público deve ser democrática ainda que, no exercício interno de suas competências, a rede privada esteja ao largo desse princípio.

Por outro lado, o artigo 37 da mesma Constituição não deixa margem a qualquer dúvida: a administração pública como um todo deve se pautar pelos princípios da moralidade, impessoalidade, legalidade, publicidade e eficiência. Aceitos como axiomáticos a legalidade, a moralidade e a publicidade, e fazendo, para essa reflexão, uma breve epochê da eficiência como desempenho qualitativo, pode-se dizer que há, na gestão do sistema, com impacto atual na área, um conjunto de forças que tensiona os caminhos de ambos os modos de gestão, ambos constitucionais: o da gestão democrática e o da gestão burocráticoimpessoal.

A gestão democrática impacta profundamente a área da Educação, que lutou pela inserção desse princípio na Constituição, contra os usos e abusos 
do autoritarismo da ditadura e seu tecnicismo e contra a tradicional (des)razão clientelística. $\mathrm{O}$ sistema democrático, contrário ao privilegiamento porque discriminatório, roga pela impessoalidade que tem, na gestão burocrática, à moda weberiana, uma de suas maneiras de busca da igualdade em nome da razão, sem outras especificações.

Pode-se, em nome da gestão democrática, esquivar-se de um sistema com traços burocratizados, no sentido weberiano? Como se furtar a uma avaliação de um bem público, serviço público exigido pela esfera jurídica do ordenamento nacional e pela contribuição da sociedade, por meio de impostos vinculados à educação? Afinal, nossos programas recrutam novos pesquisadores e docentes não por serem parentes, amigos, clientes, compadres, e sim por atributos comuns avaliados por méritos visivelmente constatados em processos concursais.

Como não postular que o exercício das funções da pós-graduação e de seus resultados não tenha uma avaliação de desempenho, aliás prevista em lei, no artigo $9^{\circ}$ e no artigo 67 da LDB?

Um sistema de avaliação de desempenho é um componente da organização da educação nacional em vista de um bem público. Ocorre que seu conteúdo não é competência da "razão de Estado" e nem da "nova razão do mundo", na feliz expressão de Dardot e Laval (2016), para significar a lógica da concorrência embutida nos órgãos de governo. Essa avaliação tem que considerar as finalidades maiores da educação e do próprio Estado Democrático de Direito.

O que se pergunta é: quais os limites dessa burocratização, funcional para os administradores, por vezes, escorregadia e realizada apenas para indicadores quantitativos? Ela se choca com ou prevalece sobre os fins de um bem público? Teria o sistema de pós-graduação se submetido de tal modo à lei férrea de Michels de modo que a busca de uma perenização funcional o tornaria insensível à participação dos pares, os quais conhecem os processos, seus limites, suas virtudes e suas insuficiências?

Não é regra da educação a "prevalência dos aspectos qualitativos sobre os quantitativos e dos resultados ao longo do período sobre os de eventuais provas finais", consoante a letra a do inciso V do art. 24 da LDB? E o art. 46 , §2 ${ }^{\circ}$, não determina o aporte, no caso das instituições públicas, verificadas deficiências, de "recursos adicionais, se necessários, para a superação" delas?

Enfim, como combinar, dentro de um "poder racional-legal", o impessoal e o democrático? Ou em outros termos: como gerir o sistema como uma espécie de Estado de Direito pelo qual se vai escoimando o arbítrio em favor do "governo das leis" e não do "governo dos homens"? Como evitar o excesso nas tarefas de controle e de coordenação? Ao mesmo tempo, como não invocar, entre pares, todos doutores, todos igualmente portadores da máxima cidadania universitária, o Estado Democrático de Direito, fundamento último da gestão democrática? 
A avaliação, sua feitura, sua gestão, são imprescindíveis para a área, para sua presença dentro do sistema de pós-graduação, porque ela é provocadora de análises e reflexões para um melhor desempenho. Por outro lado, os encontros, os seminários com suas análises e reflexões são um momento de se perceber as limitações do sistema para, em seguida, tornarem-se objeto de demandas por aperfeiçoamento do processo.

\section{Finalmente...}

Acompanhar o projeto, o processo e os produtos do PPGE-UFPR, nesses 45 anos, foi também acompanhar as "grandezas e misérias" desse sistema como um todo. Este Programa se insere em uma relação dialética entre a parte e o todo, numa perspectiva histórica.

As suas linhas de pesquisa, a sua produção científico-acadêmica, a sua presença regional, nacional e internacional e a formação de novos pesquisadores fazem jus ao lema da Universidade Federal do Paraná: Scientia et Labor. Pelo labor cotidiano de seus docentes e estudantes, trabalho consciente e crítico, o Programa segue coerente com a missão dessa Universidade: "Fomentar, construir e disseminar o conhecimento, contribuindo de forma significativa para a construção de uma sociedade crítica, equânime e solidária."

O sistema de pós-graduação conta, nesse Programa, com uma porta aberta para que a educação tenha um porto seguro que realize, de modo cada vez mais pleno, os princípios do direito à educação de qualidade, os critérios de uma pesquisa tão independente quanto compromissada por oferecer o melhor para o resgate dos princípios que regem a educação nacional.

Que a combustão do fogo vermelho, simbolizado pelo rubi desses 45 anos, se converta, daqui a 5 anos, no brilho do ouro dos 50 anos. Que este fogo, metaforizado pela nova casa do Programa, aqueça ainda mais o seu protagonismo. E que a sabedoria tranquila da maturidade tenha nele o porto seguro da pós-graduação em educação. Parabéns Programa de Pós-Graduação em Educação da Universidade Federal do Paraná! 


\section{REFERÊNCIAS}

BICUDO, Virgínia Leone. Atitudes raciais de pretos e mulatos em São Paulo. Revista Sociologia, v. 9, n. 3, p. 195-219, 1947.

BOBBIO, Norberto. Os intelectuais e o poder. São Paulo: Editora UNESP, 1997.

BOURDIEU, Pierre. Razões práticas: sobre a teoria da ação. Campinas: Papirus, 1997.

BRASIL. Presidência da República. Casa Civil. Subchefia para Assuntos Jurídicos. Constituição da República Federativa do Brasil de 1988. Brasília, 5 de outubro de 1988. Disponível em: http://www.planalto.gov.br/ccivil_03/constituicao/constituicao. htm. Acesso em: 10 out. 2020.

BRASIL. Presidência da República. Casa Civil. Subchefia para Assuntos Jurídicos. Lei n ${ }^{\circ}$ 9.394, de 20 de dezembro de 1996. Estabelece as diretrizes e bases da educação nacional. Diário Oficial da União, Brasília, DF, 23 dez. 1996. Disponível em: http:// www.planalto.gov.br/ccivil_03/leis/19394.htm. Acesso em: 10 out. 2020.

BRASIL. Ministério da Educação. Anteprojeto de lei da Reforma da Educação Superior. Brasília, 29 de julho de 2005. Disponível em: http://portal.mec.gov.br/arquivos/pdf/ acs_finalreforma280705.pdf. Acesso em: 10 out. 2020.

BRASIL. Presidência da República. Casa Civil. Subchefia para Assuntos Jurídicos. Lei $\mathrm{n}^{\circ}$ 13.005, de 25 de junho de 2014. Aprova o Plano Nacional de Educação - PNE e dá outras providências. Diário Oficial da União, Brasília, DF, 26 jun. 2014. Disponível em: http://www.planalto.gov.br/ccivil_03/_ato2011-2014/2014/lei/113005.htm. Acesso em: 10 out. 2020 .

BRASIL. Ministério da Educação (MEC). Coordenação de Aperfeiçoamento de Pessoal de Nível Superior (CAPES). Diretoria de Avaliação (DAV). Ações e programas. Avaliação quadrienal. Relatório da Avaliação Quadrienal 2017: Educação. Disponível em: www. mec.gov.br/capes. Acesso em: 12 out. 2020.

CURY, Carlos Roberto Jamil. Expansão de novos mestrados/doutorados em educação no Brasil. Boletim ANPEd, Niterói, v. 9, n. 4, out./dez. 1987.

CURY, Carlos Roberto Jamil. Quadragésimo ano do Parecer CFE n. 977. Revista Brasileira de Educação, Rio de Janeiro, v. 30, p. 7-20, 2005.

DARDOT, Pierre; LAVAL, Christian. A nova razão do mundo: ensaio sobre a sociedade neoliberal. São Paulo: Boitempo, 2016.

FÁVERO, Osmar. Situação atual e tendências de reestruturação dos programas de pósgraduação em Educação. Revista da Faculdade de Educação, São Paulo, v. 22, n. 1, jan./jun. 1996. 
GEOCAPES. Sistema de Informações Georreferenciadas: CAPES. Dados estatísticos: indicadores 2018. Disponível em: https://geocapes.capes.gov.br/geocapes/. Acesso em: 12 out. 2020.

GRAMSCI, Antonio. Concepção dialética da história. Rio de Janeiro: Civilização Brasileira, 1978.

KANT, Emanuel. A paz perpétua: ensaio filosófico. Rio de Janeiro: Brasílica, 1939.

OLIVEIRA, Betty Antunes. O Estado autoritário brasileiro e o ensino superior. São Paulo: Cortez; Campinas: Autores Associados, 1980.

SAVIANI, Dermeval. A política educacional no Brasil. In: CÂMARA BASTOS, Maria Helena; STEPHANOU, Maria (org.). Histórias e memórias da educação no Brasil. Petrópolis: Vozes, 2005. p. 30-39. v. iii, séc. XX.

UNIVERSIDADE FEDERAL DO PARANÁ (UFPR). Pró-Reitoria de Pesquisa e Pós-Graduação. Programa de Pós-Graduação em Educação. Histórico e contextualização. Disponível em: http://www.prppg.ufpr.br/site/ppge/pb/historico-econtextualizacao/\#: :text $=\mathrm{A} \% 20$ cria $\% \mathrm{C} 3 \% \mathrm{~A} 7 \% \mathrm{C} 3 \% \mathrm{~A} 3 \mathrm{o} \% 20 \mathrm{do} \% 20$ Doutorado $\% 2 \mathrm{C} \% 20$ no,tem\%C3\%A1ticas\%2C\%20as\%20linhas\%20de\%20pesquisa. Acesso em: 10 out. 2020.

Texto recebido em 22/09/2020.

Texto aprovado em 13/10/2020. 